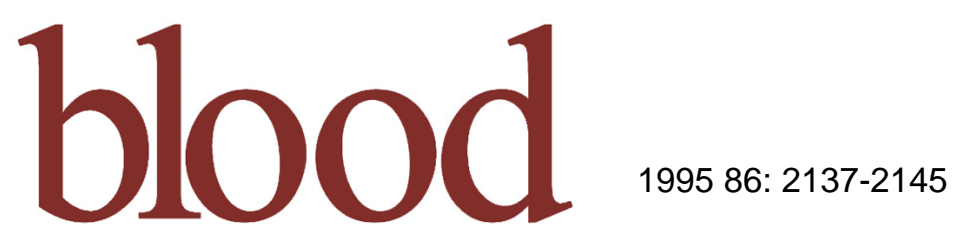

\title{
A novel single-cell proliferation assay shows that long-term culture- initiating cell (LTC-IC) maintenance over time results from the extensive proliferation of a small fraction of LTC-IC
}

CM Verfaillie and JS Miller

Information about reproducing this article in parts or in its entirety may be found online at: http://bloodjournal.hematologylibrary.org/misc/rights.dtl\#repub_requests

Information about ordering reprints may be found online at:

http://bloodjournal.hematologylibrary.org/misc/rights.dtl\#reprints

Information about subscriptions and ASH membership may be found online at: http://bloodjournal.hematologylibrary.org/subscriptions/index.dtl

Blood (print ISSN 0006-4971, online ISSN 1528-0020), is published semimonthly by the American Society of Hematology, $1900 \mathrm{M} \mathrm{St}$, NW, Suite 200, Washington DC 20036.

Copyright 2007 by The American Society of Hematology; all rights reserved.

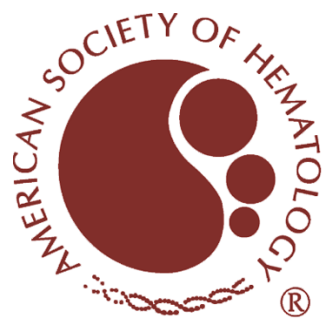




\title{
A Novel Single-Cell Proliferation Assay Shows That Long-Term Culture-Initiating Cell (LTC-IC) Maintenance Over Time Results From the Extensive Proliferation of a Small Fraction of LTC-IC
}

\author{
By Catherine M. Verfaillie and Jeffrey S. Miller
}

\begin{abstract}
We have previously shown that when adult marrow $\mathrm{CD}^{+} 4^{+} I$ HLA-DR- cells are cultured for 5 or 8 weeks in the presence of stroma-conditioned media with interleukin-3 (IL-3) and

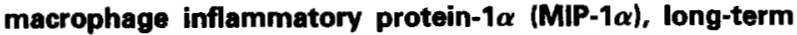
culture-initiating cells (LTC-IC) are maintained but not expanded. However, if the same cultures are evaluated after 2 weeks, we show that LTC-IC expand 5.5- \pm 0.2-fold. Because expansion of LTC-IC is likely the result of a balance between proliferation and loss of LTC-IC, we hypothesized that, although LTC-IC proliferate in these cultures, loss of a fraction of LTC-IC underlies the lack of long-term expansion. To evaluate the fate of LTC-IC (proliferation, conservation, or loss). we performed PKH-26 labeling assays and developed a single LTC-IC proliferation assay. For PKH-26 labeling assays, CD34 $^{+} /$/HLA-DR $^{-}$cells were incubated with the membrane intercallating dye, PKH-26, before culture for 14 days in stroma-noncontact cultures + IL-3 + MIP-1 . Progeny was reselected by fluorescence-activated cell sorting based on their PKH-26 fluorescence intensity. These studies showed that LTC-IC proliferate because $80 \%$ of LTC-IC at week 2 had 0.5 to $1 \mathrm{log}$ lower fluorescence intensity than did freshly labeled CD34 ${ }^{+} /$HLA-DR $^{-}$cells. To further determine the fate
\end{abstract}

$\mathbf{T}$ HE USE OF SELECTED CD $34^{+}$cells and CD $34^{+}$subpopulations as autografts and the advent of human hematopoietic stem cell gene therapy approaches have set the stage for attempts to expand human hematopoietic stem cells ex vivo. ${ }^{1.7}$ Although a variety of cultures have been described that allow expansion of committed clonogenic cells, no culture condition has thus far been described that allows longterm expansion of more primitive hematopoietic progenitors, including long-term culture-initiating cells (LTC-IC) and multipotent stem cells that can fully reconstitute lethally irradiated hosts.

Three systems have been developed for ex vivo culture of candidate stem cell populations: Dexter-type stroma-contact cultures, ${ }^{8-11}$ stroma-free cultures supplemented with cytokines, ${ }^{12-15}$ and a culture system described by us termed stroma-noncontact culture. ${ }^{16-18}$ Although culture of human marrow in a Dexter-type stroma-contact culture for up to 2 weeks may at least preserve human transplantable hematopoietic stem cells ${ }^{12}$ and may expand primitive LTC-IC,${ }^{9}$ culture of primitive progenitors in such cultures for 5 or more weeks maintains only $20 \%$ of LTC-IC. ${ }^{16,19}$ Similarly, although primitive progenitors can be induced to differentiate in stroma-free, cytokine-supplemented long-term cultures, studies from several laboratories indicate that LTC-IC are not expanded nor maintained in these cultures beyond 2 weeks. ${ }^{15,17,18}$

We have recently shown that a fraction of primitive LTCIC present in $\mathrm{Lin}^{-} / \mathrm{CD} 34^{+} / \mathrm{HLA}-\mathrm{DR}^{\text {low }}$ (DR ${ }^{-}$cells) are maintained when cocultured with stroma but are separated from the stromal layer by a $0.4-\mu \mathrm{m}$ microporous membrane (stroma-noncontact cultures). ${ }^{16}$ Furthermore, LTC-IC are maintained when cultured in the absence of stroma but when supplemented daily by media conditioned by stromal feeders (stroma-conditioned media culture) ${ }^{17}$ The addition of growth of LTC-IC, we also developed a single LTC-IC proliferation assay. A population of $\mathrm{CD}^{+} 4^{+} / \mathrm{CD}^{-} 3^{-}$cells, highly enriched in LTC-IC, was sorted singly in stroma-conditioned media + IL-3 + MIP-1a. After 5 weeks, the content of each well was divided equally over 8 secondary stroma-containing wells and cultured for 8 weeks to determine the capacity of the single-cell progeny to initiate 1 or more secondary stromal cultures. Progeny of single-sorted cells were able to initiate up to 8 secondary long-term cultures, demonstrating that LTC-IC proliferate in stroma-conditioned media + IL-3 + MIP$1 \alpha$. However, more than $65 \%$ of single-sorted LTC-IC were not conserved because their progeny could no longer initiate secondary long-term cultures. This finding indicates that, although stromal factors and IL-3 + MIP-1 $\alpha$ can induce proliferation of LTC-IC, failure to conserve a large fraction of LTCIC results in lack of long-term expansion. Insight into the fate of individual LTC-IC should now allow us to design culture systems that increase not only proliferation but also conservation of LTC-IC, ultimately leading to long-term ex vivo stem cell expansion.

(C) 1995 by The American Society of Hematology.

promoting cytokines alone to stroma-noncontact cultures results in the exhaustion of LTC-IC by 5 and 8 weeks of culture. ${ }^{17,18}$ In contrast, the combined addition of interleukin3 (IL-3) and the chemokine macrophage inflammatory protein-1 $\alpha$ (MIP-1 $\alpha$ ) to stroma-noncontact or stroma-conditioned media cultures results in complete maintenance of LTC-IC for at least 8 weeks. ${ }^{18}$ However, no net increase or expansion of LTC-IC was seen after 8 weeks under these culture conditions.

We hypothesized that ex vivo expansion of LTC-IC beyond 2 to 3 weeks will not only require that LTC-IC proliferate but that a large fraction of the starting LTC-IC population survives in its undifferentiated state. Bulk LTC-IC expansion assays, in which the number of LTC-IC present in the starting cell population is compared with that present after vari-

From the Division of Hematology, University of Minnesota, Minneapolis, $M N$.

Submitted February 21, 1995; accepted May 9, 1995.

Supported in part by National Institutes of Health Grants No. RO1-HL-49930-01A2, ROI-HL-48738-01, RO1-CA-4581401, and PO1-CA-21737; the Paul Christiansen Foundation; the University of Minnesota Bone Marrow Transplant Research Fund; The Leukemia Task Force; the University of Minnesota Hospitals and Clinics; the Leukemia Society of America; and the "Fundacion Internacional Jose Carreras Para La Lucha Contra La Leucemia."

Address reprint requests to Catherine $M$. Verfaillie, MD, Box 480 UMHC, University of Minnesota, 420 Delaware St SE, Minneapolis, $M N, 55455$.

The publication costs of this article were defrayed in part by page charge payment. This article must therefore be hereby marked "advertisement" in accordance with 18 U.S.C. section 1734 solely to indicate this fact.

(C) 1995 by The American Society of Hematology.

0006-4971/95/8606-0016\$3.00/0 
able periods of culture in expansion systems, cannot assess whether individual LTC-IC have proliferated or are conserved. ${ }^{16-18}$ Therefore, we used a PKH-26 labeling assay that can determine whether LTC-IC proliferate. In addition, we developed a single-cell proliferation assay that can determine the fate of individual LTC-IC. This assay now allows us to examine at a single LTC-IC level if specific culture conditions are conducive for proliferation (ie, a single LTC-IC undergoing a self-renewing cell division) and conservation (ie, persistence of a single LTC-IC over time). The capacity to determine the fate of individual LTC-IC should now allow us to specifically alter culture conditions to increase both conservation and proliferation, ultimately leading to longterm ex vivo expansion of human hematopoietic stem cells.

\section{MATERIALS AND METHODS}

Selection of $\mathrm{Lin}^{-} \mathrm{CD} 34^{+} H L A-D R^{-}$cells (DR cells). Marrow samples were aspirated from the posterior iliac crest of healthy, young volunteers after informed consent was obtained using guidelines approved by the Committee on the Use of Human Subjects at the University of Minnesota. $\mathrm{Lin}^{-} \mathrm{CD} 34^{+} \mathrm{HLA}-\mathrm{DR}{ }^{-}$cells $\left(\mathrm{DR}^{-}\right)$ were selected using fluorescence-activated cell sorting (FACS) as previously described. ${ }^{3.16 .20}$

Stroma-noncontact cultures. Complete long-term bone marrow culture (LTBMC) media consisted of Iscove's modified Dulbecco's medium (IMDM) with $12.5 \%$ fetal calf serum (Hyclone, Logan, UT), $12.5 \%$ horse serum (Terry Fox Laboratories, Vancouver, British Columbia, Canada), $2 \mathrm{mmol} / \mathrm{L}$ L-glutamine (GIBCO Laboratories, Grand Island, NY), 1,000 U/mL penicillin, $100 \mathrm{U} / \mathrm{mL}$ streptomycin (GIBCO Laboratories), and $10^{-6} \mathrm{~mol} / \mathrm{L}$ hydrocortisone. ${ }^{20}$ Stromanoncontact cultures consisted of allogeneic-irradiated stroma subcultured in the bottom well of 6-well plates. A collagen-treated transwell insert (0.4- $\mu \mathrm{m}$ filter; Costar, Cambridge, MA) was placed above the stromal layer, and 4.5 to $14 \times 10^{3} \mathrm{DR}^{-}$cells were plated in the upper well. Cultures were maintained in a humidified atmosphere at $37^{\circ} \mathrm{C}$ and $5 \% \mathrm{CO}_{2}$. Stroma-noncontact cultures were fed at weekly intervals by removing half the media from the bottom wells and replacing it with fresh complete media with cytokines as indicated.

Cytokines. MIP- $1 \alpha$ was purchased from R\&D Systems (Minneapolis, MN). IL-3, IL-6, and IL-11 were generous gifts from the Genetics Institute (Boston, MA). MIP- $1 \alpha(100 \mathrm{ng} / \mathrm{mL})$ and IL-3 (5 $\mathrm{ng} / \mathrm{mL}$ ) were added once weekly to stroma-noncontact cultures to generate $\mathrm{CD} 34^{+} \mathrm{CD} 33^{-}$cultured cells used in single-cell proliferation assays as well as in PKH-26 proliferation assays. MIP- $] \alpha$ (100 $\mathrm{ng} / \mathrm{mL}), \mathrm{IL}-3(5 \mathrm{ng} / \mathrm{mL}), \mathrm{IL}-6(5 \mathrm{ng} / \mathrm{mL})$, and $\mathrm{IL}-11(20 \mathrm{ng} / \mathrm{mL})$ were added to stroma-conditioned media used to feed single-cell proliferation assays.

Stromal feeders and stroma-conditioned media. Marrow stromal feeders were established in T150 flasks (Costar) as previously described. ${ }^{20}$ Once confluent, stromal layers were irradiated at 1,250 $\mathrm{Gy}$ and subcultured in wells of 6-well plates. Alternatively, stromal feeders were maintained in T150 flasks. After a first half media change 7 days after irradiation, $50 \%$ of the media was removed every 2 to 4 days and frozen at $-20^{\circ} \mathrm{C}$ as day 2 to 4 stromaconditioned media. Media was thawed a maximum of 10 days before use in stroma-conditioned media cultures, spun at $1,000 \mathrm{~g}$ to remove all debris, supplemented as indicated with cytokines, and stored at $4^{\circ} \mathrm{C}$.

M2-10B4 cells, a generous gift from Dr C. Eaves (Vancouver, British Columbia, Canada), were maintained in RPMI (GIBCO Laboratories) $+10 \%$ fetal calf serum. We and others have shown that these murine marrow stroma-derived fibroblasts can support human hemopoiesis in stroma-contact and stroma-noncontact cultures to the same extent as normal human marrow stromal feeders. ${ }^{21,22}$ M2-10B4 cells were subcultured in wells of 96-well plates. Once confluent, plates were irradiated with $6,000 \mathrm{~Gy}$ and the media was changed to LTBMC media. ${ }^{20}$

Assessment of LTC-IC expansion by limiting dilution analysis $(L D A)$. Ten thousand $\mathrm{DR}^{-}$cells were plated in limiting dilutions onto M2-10B4 feeders (22 replicates; $300,100,33$, and 11 cells/ well) on day 0 . Ten thousand $\mathrm{DR}^{-}$cells were also plated in stromanoncontact cultures with the indicated cytokines, as previously described. ${ }^{16-18}$ After 2, 5, or 8 weeks, $\mathrm{DR}^{-}$-derived progeny were replated in LDA onto M2-10B4 feeders (22 replicates and concentrations equivalent to $300,100,33$, or 11 freshly sorted $\mathrm{DR}^{-}$cells). These cultures were maintained for 5 weeks by exchanging the medium weekly (LTBMC medium without cytokines) and the feeders were overlayed with methylcellulose progenitor culture medium containing 3 IU erythropoietin (Epoietin; Amgen, Thousand Oaks, CA) and $10 \% 5637$ bladder $\mathrm{Ca}$ cell line supernatant. ${ }^{16}$ Wells were evaluated for the presence of secondary clonogenic cells 2 weeks later and the absolute number of LTC-IC present was calculated using Poisson statistics. ${ }^{16,19}$ Fold expansion was calculated as the number of LTC-lC in cultured progeny divided by the number of LTC-IC present in freshly sorted cells.

Assessment of LTC-IC proliferation by PKH-26 labeling. Freshly sorted $\mathrm{DR}^{-}$cells were labeled with PKH-26 (Zynaxis, Malvern, $\mathrm{PA}$ ) according to the manufacturer's recommendations. ${ }^{15,23}$ Fifty thousand PKH-26-labeled DR ${ }^{-}$cells were cultured in stromanoncontact cultures supplemented either without cytokines or in the presence of $100 \mathrm{ng} / \mathrm{mL} \mathrm{MIP-1} \alpha$ and $5 \mathrm{ng} / \mathrm{mL}$ IL-3 for 12 to 14 days. Progeny were recovered from the transwells and subjected to a second FACS sort, now based on PKH-26 fluorescence intensity as shown in Fig 2A. Windows were chosen that contained cells with the same or $0.5 \log$ lower PKH-26 fluorescence intensity $(\mathrm{R} 1+2)$, $1 \log$ lower (R3), and $1.5 \mathrm{log}$ lower (R4) PKH-26 fluorescence intensity compared with the unexpanded cell population. Cells reselected from these windows were then replated in LDA on M2-10B4 feeders for 5 weeks to enumerate the absolute number of LTC-IC present.

Assessment of LTC-IC proliferation by single-cell proliferation assay. DR" cells were cultured for 2 weeks in stroma-noncontact cultures supplemented with MIP- $1 \alpha$ and IL-3 $(100 \mathrm{ng} / \mathrm{mL}$ and $5 \mathrm{ng} /$ $\mathrm{mL}$, once weekly, respectively). ${ }^{17,24}$ Cells were then reselected by FACS according to their CD34 and CD33 antigen expression as described ${ }^{24}$ In contrast to freshly sorted DR cells, which contain approximately $1 \% \mathrm{LTC}-\mathrm{IC},{ }^{16}$ cultured $\mathrm{CD} 34^{+} \mathrm{CD} 33^{-}$cells contain up to $30 \%$ LTC-IC, allowing evaluation of LTC-IC at the singlecell level. $\mathrm{CD} 34^{+} \mathrm{CD} 33^{-}$cells present in IL-3 + MIP- $1 \alpha$-cultured progeny were sorted singly in wells of flat-bottom 96-well plates (Costar) containing either LTBMC media not conditioned by marrow stromal feeders or day 2 to 4 stroma stroma-conditioned media supplemented with cytokines as indicated, using the single-cell deposition device on a FACS Star Plus flow cytometry system (Becton Dickinson, Mountain View, CA). Wells were inspected 12 to 24 hours after the FACS sort to ascertain that only I cell per well was present. We were able to detect 1 cell/well in approximately $80 \%$ of wells and no cells in $20 \%$ of the wells. In no instance was more than 1 cell detected. Fresh media with cytokines was added 5 days per week for a total of 4 to 5 weeks. The contents of each well was then divided equally over wells of 8 secondary 96-well plates containing M2-10B4 feeders (Fig 3A) in such a fashion that one eighth of the single-cell progeny was deposited in the same location in all 8 secondary plates. These secondary stromal cultures were maintained for an additional 6 to 8 weeks and the feeders were overlayed with methylcellulose progenitor culture media. ${ }^{16}$ After 14 days, the wells were scored for the presence of colony-forming cells (CFC), In a limited number of experiments, the contents of the wells 
Table 1. Definitions

\begin{tabular}{ll}
$\begin{array}{l}\text { Bulk population } \\
\text { Expansion }\end{array}$ & $\begin{array}{r}\text { Recovery of }>100 \% \text { of LTC-IC present in the } \\
\text { starting population } \\
\text { Recovery of } 1 \% \text { to } 100 \% \text { of LTC-IC present } \\
\text { in the starting population }\end{array}$ \\
$\begin{array}{c}\text { Single-cell level } \\
\text { Proliferation }\end{array}$ & $\begin{array}{l}\text { A single cell that gives rise to two or more } \\
\text { LTC-IC, ie, can initiate hemopoiesis in at } \\
\text { least } 2 \text { secondary stromal cultures. } \\
\text { A single cell that survives over time with or } \\
\text { without proliferation, ie, can initiate } \\
\text { hematopoiesis in at least one secondary } \\
\text { stromal culture. } \\
\text { A single cell that fails to survive, ie, cannot } \\
\text { initiate hematopoiesis in secondary } \\
\text { stromal cultures. }\end{array}$ \\
\hline
\end{tabular}

were removed, cytospun, and Wright-Giemsa-stained to evaluate the cell type present in secondary CFC. This assay allows us to assess proliferation and conservation of single LTC-IC, as defined in Table 1.

Statistical analysis. Results of experimental points from multiple experiments were reported as the mean \pm standard error of the mean (SEM). Significance levels were determined using the twosided Student's $t$-test.

\section{RESULTS}

In a first set of experiments we compared the absolute number of LTC-IC present after 2, 5, and 8 weeks in stromanoncontact cultures with the absolute number of LTC-IC present in freshly sorted cells. Ten thousand $\mathrm{DR}^{-}$cells were plated in LDA onto M2-10B4 feeders on day 0 and in stroma-noncontact cultures with either no cytokines, IL-3 + MIP-1 $\alpha$, or IL-3 + MIP- $1 \alpha+$ IL-6 + IL-11. After 2, 5, or 8 weeks, progeny of $\mathrm{DR}^{-}$cells were replated in LDA on secondary M2-10B4 feeders for 5 weeks. ${ }^{16-18}$ Evaluation at 2 weeks showed that the absolute number of LTC-IC increased $1.4- \pm 0.25$-fold when $\mathrm{DR}^{-}$cells were cultured in stroma-noncontact cultures in the absence of cytokines, 5.5\pm 0.2 -fold when cultured in IL-3 + MIP- $1 \alpha$ supplemented stroma-noncontact cultures, and 2.9- \pm 0.1 -fold when cultured in the presence of IL-6 and IL-11 in addition to IL-3 and MIP-1 $\alpha$ (Fig 1). However, as we have shown previously, when $\mathrm{DR}^{-}$cells were cultured for 5 or 8 weeks in either culture system, no LTC-IC expansion was seen. One hundred percent of LTC-IC were maintained when cultured in the presence of IL-3 and MIP- $1 \alpha$ for 5 to 8 weeks. Interestingly, less than $50 \%$ of LTC-IC were maintained for 5 to 8 weeks when cultured in the presence of multiple growth-promoting cytokines and MIP- $1 \alpha$. These studies suggest that a combination of IL-3, MIP-1 $\alpha$, and stroma-conditioned media may induce proliferation of LTC-IC and therefore result in a net early increase in the total number of LTC-IC. Alternatively, expansion of the total number of LTC-IC early on during culture could be the result of recruitment of quiescent LTCIC. However, failure to expand LTC-IC for prolonged periods of time suggests that LTC-IC may not survive as a result of terminal differentiation or cell death.
To show LTC-IC proliferation, we used the membrane intercalating fluorochrome PKH-26. PKH-26 is an aliphatic fluorochrome that incorporates in the lipid bilayer of cytoplasmic membranes. ${ }^{15,22}$ Upon cell division, the label is partitioned between daughter cells and the fluorescence intensity of daughter cells is approximately one half that of the parent cell. No transfer of dye between labeled and nonlabeled cells has been shown. PKH-26 fluorescence intensity can therefore provide a semiquantitative measure for cell proliferation. $\mathrm{PKH}-26$-labeled $\mathrm{DR}^{-}$cells were cultured for 14 days in cytokine-free or IL-3 + MIP- $1 \alpha$ supplemented stromanoncontact cultures. $\mathrm{DR}^{-}$-derived progeny were then subjected to a second FACS sort based on PKH-26 fluorescence intensity (Fig 2A). Reselected cells present in the windows $\mathrm{R} 1+2, \mathrm{R} 3$, and $\mathrm{R} 4$ were replated in $\mathrm{LDA}$ on $\mathrm{M} 2-10 \mathrm{~B} 4$ to evaluate the number of LTC-IC present. As shown in Fig $2 \mathrm{~B}$, only $19 \% \pm 7 \%$ of LTC-IC recovered from IL-3 + MIP$1 \alpha$ supplemented cultures were present in $\mathrm{R} 1+2$, which has PKH-26 fluorescence intensity similar to or $1 / 2 \log$ lower than that of nonexpanded $\mathrm{DR}^{-}$cells. However, $75 \% \pm 8 \%$ of LTC-IC were recovered in window R3, which has 1 log lower PKH-26 fluorescence intensity than freshly labeled $\mathrm{DR}^{-}$cells. For stroma-noncontact cultures not supplemented with cytokines, $49 \% \pm 10 \%$ of LTC-IC were recovered in window $\mathrm{R} 1+2$ and $51 \% \pm 10 \%$ were recovered in window R3. These studies suggest that the net increase in LTC-IC seen in IL-3 + MIP- $1 \alpha$ supplemented stroma-noncontact cultures is at least in part the result of increased proliferation of LTC-IC rather than simple recruitment of quiescent LTCIC. Although PKH-26-labeling assays provide indirect evidence that LTC-IC proliferation underlies the initial LTCIC expansion, they fail to explain the lack of expansion of LTC-IC for 5 to 8 weeks under any of the described culture conditions.

To further evaluate the fate of LTC-IC in culture, we developed a single-cell proliferation assay. A population highly enriched in LTC-IC was sorted singly in the wells of a 96-well plate containing cytokines and stroma-conditioned media. Previous studies from our laboratory have shown that $\mathrm{CD} 34^{+} \mathrm{CD} 33^{-}$cells recovered from IL-3 + MIP- $1 \alpha$ supplemented stroma-noncontact cultures contain approximately $10 \%$ to $30 \%$ cells capable of initiating long-term cultures or LTC-IC. ${ }^{24}$ Such CD $34^{+} \mathrm{CD} 33^{-}$cells were used in the single-cell proliferation assays. Wells were inspected 12 to 24 hours after the sort to assure that only 1 cell was present per well. Cultures were maintained by exchanging half the media 5 days per week with fresh stroma-conditioned media with cytokines. After 4 to 5 weeks, the contents of each well was divided equally over $8 \mathrm{M} 2-10 \mathrm{~B} 4$ feeder containing plates in such a manner that one eighth of the cells was deposited in the same location of the 8 secondary plates. After 8 weeks, all media was removed and the stromal feeders were overlayed with cytokine-containing methylcellulose media to determine the presence or absence of secondary clonogenic cells, representing progeny of LTC-IC deposited 8 weeks earlier. As shown in Fig $3 \mathrm{~A}$ and Table 1, this allows us to assess whether an LTC-IC has proliferated, was conserved, or did not survive and was lost.

A total of $16.5 \% \pm 2 \%$ of single $\mathrm{CD} 34^{+} \mathrm{CD} 33^{-}$cells 


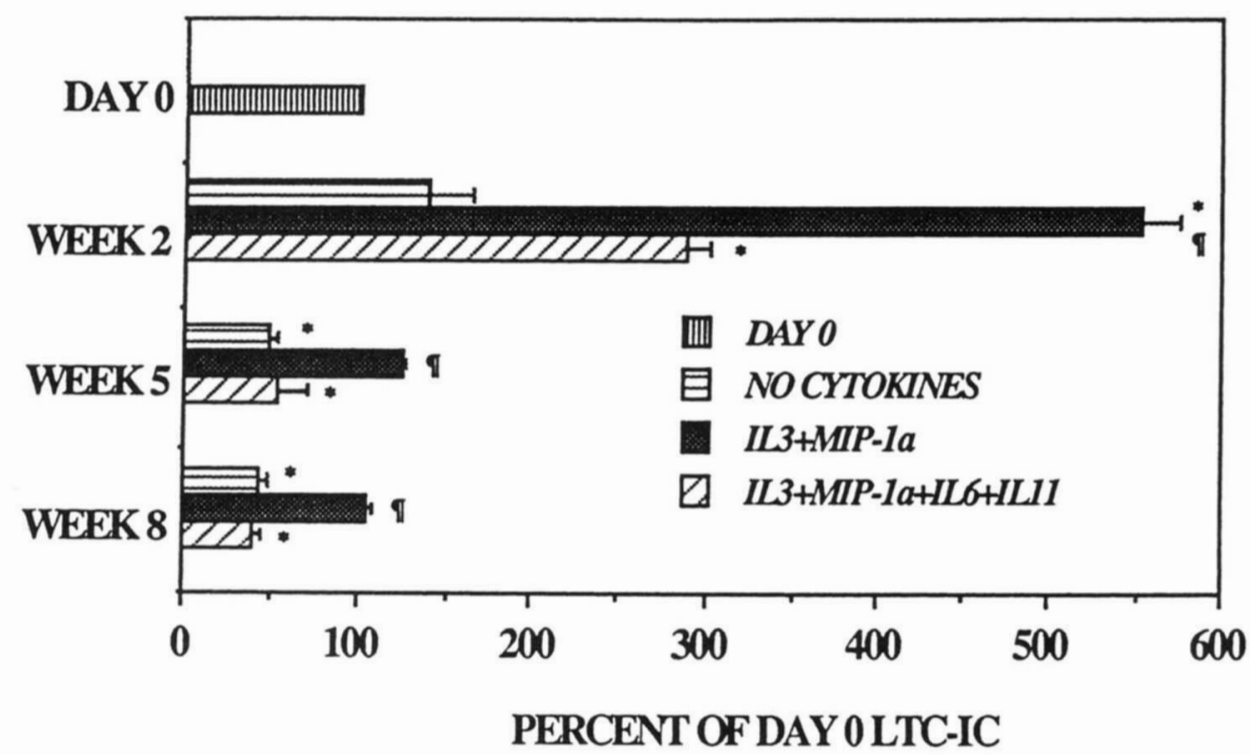

Fig 1. LTC-IC expand after 2 but not after 5 or 8 weeks in stroma-noncontact cultures supplemented with IL-3 + MIP-1 $\alpha$. Ten thousand $\mathrm{DR}^{-}$cells were plated in stroma-noncontact $\left(N=3\right.$ to 9 ) cultures with or without cytokines as indicated. After 2,5, or 8 weeks, DR ${ }^{-}$-derived progeny were replated in LDA on M2-10B4 feeders to determine the absolute number of LTC-IC still present. The absolute number of LTC-IC present after 2,5 , or 8 weeks was compared with that present in freshly sorted $\mathrm{DR}^{-}$cells $(=100 \% ; 0.75 \pm 0.1 \mathrm{LTC}$-IC per 100 freshly sorted $\mathrm{DR}^{-}$cells). Differences between day 0 and week 2,5 , or 8 : ${ }^{*} \boldsymbol{P}<.05$. Differences between IL-3 $+\mathrm{MIP}-1 \alpha$ and the other two culture conditions: $\uparrow P<.05$.

sorted immediately in contact with M2-10B4 feeders and cultured for 8 weeks were capable of generating CFC and therefore had LTC-IC capacity. The number of secondary CFC per LTC-IC varied between 1 and 10. Colonies recovered consisted mainly of colony-forming unit-granulocytemacrophage (CFU-GM), colony-forming unit-granulocyte (CFU-G), and colony-forming unit-macrophage (CFU-M), but only rare burst-forming unit-erythroid (BFU-E) or CFUMIX. In contrast, when single $\mathrm{CD} 34^{+} \mathrm{CD} 33^{-}$cells were cultured for 4 to 5 weeks in stroma-noncontact cultures supplemented with IL-3 + MIP- $1 \alpha$ and their progeny were replated in contact with stromal feeders, only 4 to 8 cells per 88 sorted cells $(5.6 \% \pm 1.4 \%)$ were capable of initiating and sustaining hematopoiesis in at least one secondary stromal culture (conserved LTC-IC; Fig 3B). This finding suggests that a large proportion of LTC-IC was lost under these culture conditions. However, $80.5 \% \pm 7 \%$ of $\mathrm{CD} 34^{+} / \mathrm{CD} 33^{-}$ progeny that were able to reinitiate long-term cultures after the initial 5 weeks in stroma-conditioned media + IL-3 + MIP- $1 \alpha$ culture contained more than 1 LTC-IC, because they could initiate 2 to 8 secondary stromal long-term cultures. This finding shows at the single-cell level that LTC-IC cultured in the presence of stromal factors and IL- $3+$ MIP- $1 \alpha$ proliferate. Examination of clonogenic progeny present in the secondary stromal cultures showed the presence of 1 to $10 \mathrm{CFU}-\mathrm{GM}$, CFU-G, and/or CFU-M colonies per well, whereas only rare BFU-E or CFU-MIX colonies were observed. The type and number of colonies recovered from progeny of cells cultured for 5 weeks in stroma-conditioned media culture was similar to that seen for $\mathrm{CD} 34^{+} \mathrm{CD} 33^{-}$ cells sorted immediately in M2-10B4 contact cultures without prior expansion in stroma-noncontact cultures. This indi- cates that primitive progenitors with similar functional capacity as those present in freshly sorted cells were conserved and had proliferated.

Because LTC-IC maintenance is significantly lower when $\mathrm{DR}^{-}$cells are cultured in stroma-noncontact cultures supplemented not only with IL-3 + MIP- $1 \alpha$ but also with IL-6 and IL-11, we hypothesized that this would be caused by increased loss of LTC-IC rather than lack of LTC-IC proliferation. We used the single-cell proliferation assay to examine the effect of IL- 6 and IL-11 on the conservation and proliferation of single-sorted LTC-IC. The addition of IL-6 + IL-11 to IL-3 + MIP- $1 \alpha$ containing stroma-conditioned media cultures resulted in a significantly greater loss of LTCIC after 4 to 5 weeks $(P=.003)$. Indeed, in only 4 of 6 experiments (Fig 3C) were we able to show that LTC-IC were conserved after the initial 4 to 5 weeks of culture. However, almost all such LTC-IC initiated multiple secondary M2-10B4 stromal cultures $(93.7 \% \pm 3.7 \%)$. This finding indicates that failure to maintain LTC-IC under these conditions is the result of excessive loss of LTC-IC and not failure to induce their proliferation.

The total number of LTC-IC present in all 8 secondary stromal cultures initiated (Fig 3B) with progeny of cells sorted singly in IL-3 and MIP- $1 \alpha$ containing stroma-conditioned media was $20.1 \% \pm 1.4 \%$ of the initial sorted $\mathrm{CD}_{4} 4^{+} \mathrm{CD} 33^{-}$cells (Fig 4 ) or $125 \%$ of $\mathrm{CD} 34^{+} \mathrm{CD} 33^{-}$cells cultured immediately after the sort in contact with stromal feeders $(P=.17)$. These numbers are in accordance with observations made in bulk LTC-IC expansion cultures that $126 \% \pm 2 \%$ of LTC-IC are maintained for 5 weeks (Figs 1 and 4). Similarly, the total number of LTC-IC that was recovered from all 8 secondary stromal plates initiated with prog- 


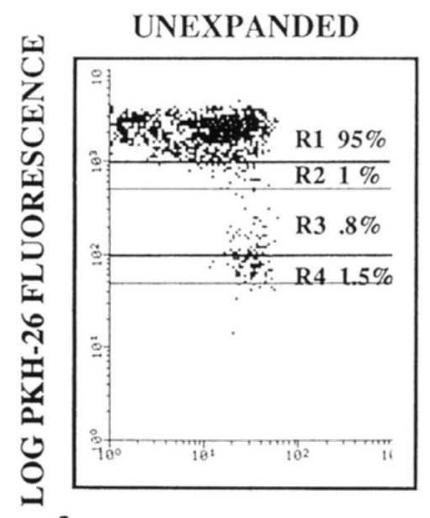

NO CYTOKINES

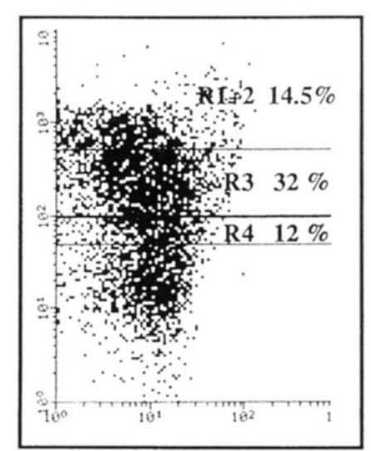

MIP- $1 \alpha+\mathrm{IL} 3$

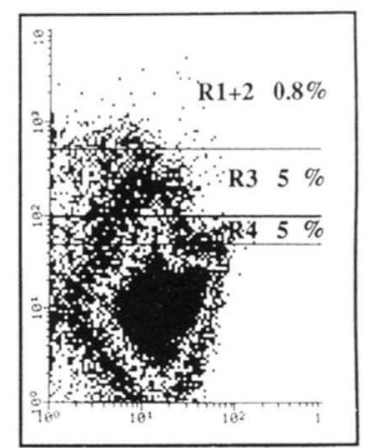

A
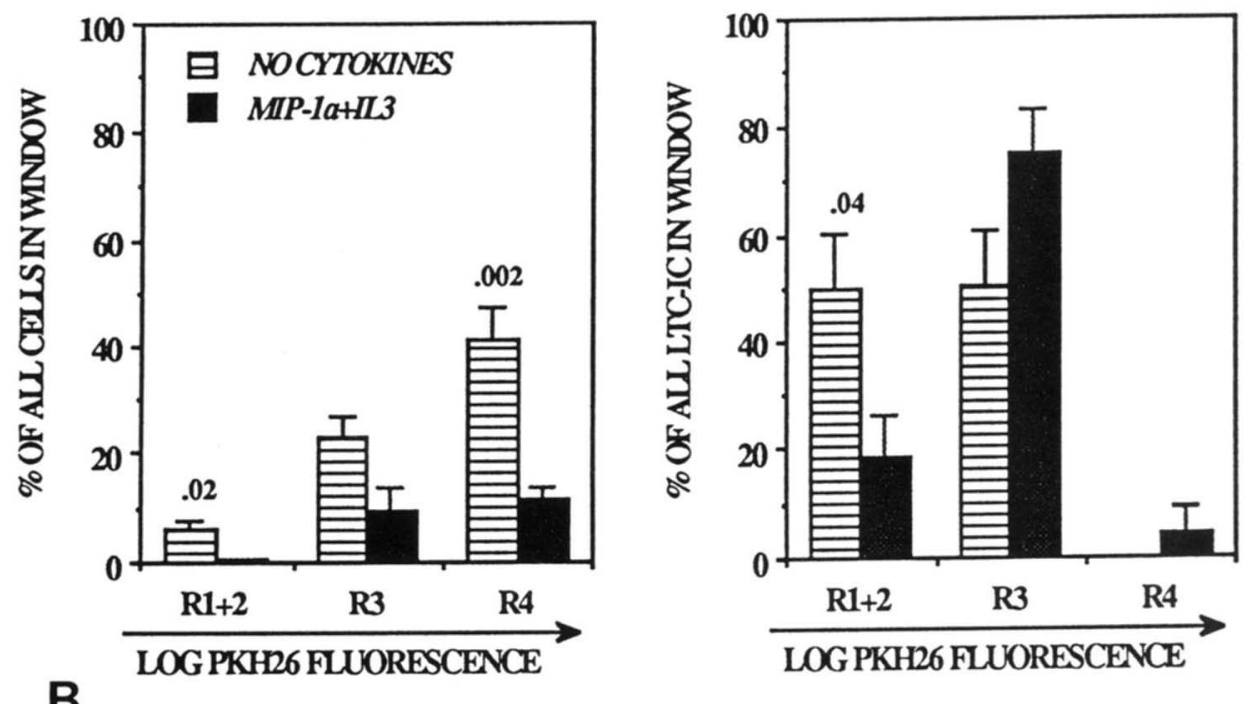

Fig 2. LTC-IC proliferate more in IL-3 + MIP- $1 \alpha$ supplemented than in cytokine-free stroma-noncontact cultures. Freshly sorted DR ${ }^{-}$cells were labeled with PKH-26 as per the manufacturer's recommendations and plated in cytokine-free or IL-3 + MIP-1 $\alpha$ supplemented stromanoncontact cultures for 2 weeks. Cell expansion in IL-3 + MIP- $1 \alpha$ supplemented cultures was 15.5- \pm 4.1-fold (N $=6$ ) and in cytokine-free cultures 2.6- \pm 0.8 -fold $(\mathrm{N}=7)$. Fifty thousand $\mathrm{PKH}-26$-labeled cells were also fixed in $2 \%$ paraformaldehyde and kept for 14 days at 4 or $37^{\circ} \mathrm{C}$ as unexpanded control. Cultured $\mathrm{DR}^{-}$-derived progeny were reselected by FACS based on their PKH-26 fluorescence intensity. Windows encompassing cells with fluorescence intensity similar to or $0.5 \log \operatorname{lower}(\mathbf{R} 1+2), 1 \log$ lower $(\mathbf{R} 3)$, or $1.5 \log \operatorname{lower}(\mathbf{R} 4)$ than that of unexpanded $\mathrm{DR}^{-}$cells were used. Cells recovered in these windows were replated in LDA in secondary M2-10B4 cultures for 5 weeks to evaluate the number of LTC-IC present. The percent LTC-IC recovered in a specific window was calculated as: $100 \times$ Ithe absolute number of LTC-IC per replated cell times the overall percent of cells recovered in that window). For IL-3 + MIP-1 $\alpha$ supplemented cultures, the LTC-IC frequency in $\mathrm{R} 1+2$ was $0.63 \% \pm 0.26 \%$; in R3, $0.35 \% \pm 0.13 \%$; and in $\mathbf{R} 4,0.04 \% \pm 0.04 \%$. For cytokine-free stroma-noncontact cultures, the frequency of LTC-IC in R1 +2 was $0.52 \% \pm 0.13 \%$ and in $\mathrm{R} 3$ was $0.18 \% \pm 0.06 \%$.

eny derived from IL-3 + MIP- $1 \alpha+$ IL- $6+$ IL-11 supplemented stroma-conditioned media cultures was $8.5 \% \pm$ $3.24 \%$ of the initially sorted $\mathrm{CD} 34^{+} \mathrm{CD} 33^{-}$cells or $52.8 \%$ of that recovered from single-cell assays in which unexpanded $\mathrm{CD} 34^{+} \mathrm{CD} 33^{-}$cells were plated immediately in contact with stromal feeders (Fig 4). Again, these results are similar to those observed for bulk LTC-IC expansion cultures in which $52 \% \pm 17 \%$ of LTC-IC were maintained for 5 weeks in stroma-noncontact cultures containing IL- $3+$ MIP- $1 \alpha+$ IL$6+$ IL-11. This demonstrates further that the percentage of LTC-IC maintained in stroma-noncontact cultures supplemented with cytokines is the net result of the proliferation of a small fraction of the starting LTC-IC population.

\section{DISCUSSION}

Although LTC-IC can be expanded when cultured short term ex vivo, no net expansion is seen when these progenitors are cultured for 5 to 8 weeks. We hypothesized that the lack of long-term expansion is caused by loss of a significant fraction of LTC-IC due to either terminal differentiation or cell death. To design culture conditions that will expand primitive progenitors long term, it will be necessary to develop methods that can determine the fate of LTC-IC in ex vivo cultures. Although comparison of the number of LTCIC in the starting population with that after culture under expansion conditions shows whether LTC-IC have been expanded or were maintained, this technique does not allow 

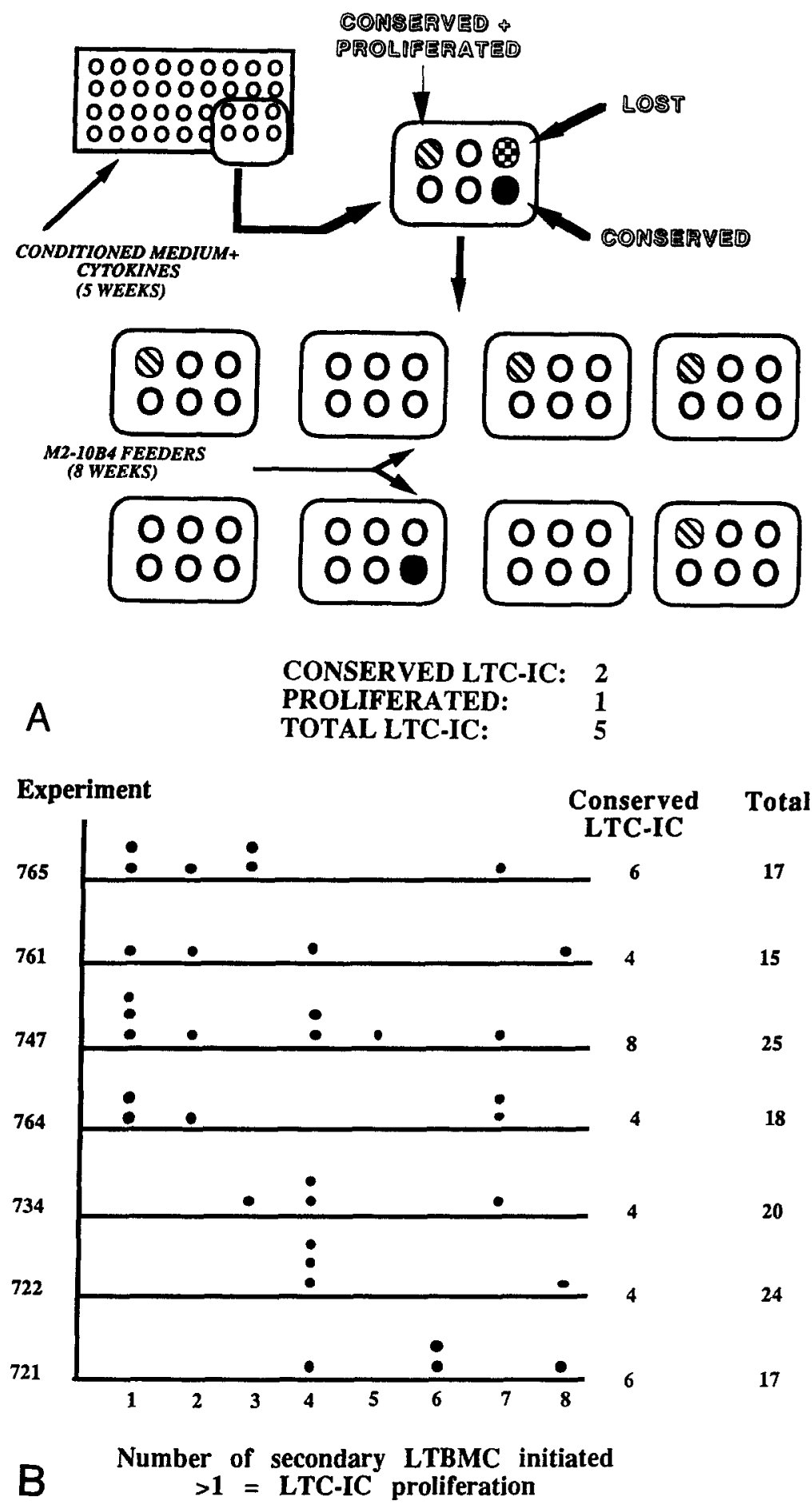

us to determine the contribution of conservation and proliferation of LTC-IC to the overall expansion/maintenance.

We therefore developed a single-cell proliferation assay that allows us to determine if an individual LTC-IC was conserved and had proliferated over time. We demonstrate that single LTC-IC cultured in stroma-derived soluble factors in combination with IL-3 + MIP- $1 \alpha$ or IL-3 + IL- $6+$ IL$11+$ MIP- $1 \alpha$ proliferate, because progeny of most surviving
Fig 3. Single-cell proliferation assay. DR- cells were cultured for 2 weeks in stroma-noncontact culTotal tures supplemented with IL-3 + MIP- $1 \alpha 15 \mathrm{ng} / \mathrm{mL}$ and $100 \mathrm{ng} / \mathrm{mL}$, once weekly). CD34 ${ }^{+} \mathrm{CD}^{-} 3^{-}$cells present in IL-3 + MIP-1 $\alpha$ cultured progeny were sorted singly in 88 wells of flat-bottom 96-weil plates containing day 2 to 4 stroma-conditioned media supplemented with cytokines as indicated using the single-cell deposition device on a FACS Star Plus flow cytometry system (1 to 3 plates per condition, per experiment). Fresh stroma-conditioned media with cytokines was added 5 days per week for a total of 4 to 5 weeks. The content of each well was then divided equally over 8 secondary 96-well plates containing M2-10B4 feeders such that one eighth of the progeny was deposited in the same location in all 8 secondary plates. Secondary stromal cultures were maintained for an additional 8 weeks and the feeders were overlayed with methylcellulose progenitor culture media. After 14 days, the wells were scored for the presence of CFC. As shown in (A), the LTC-IC in the black well was conserved, because an LTC-IC was recovered in 1 of the 8 wells of the secondary stromal cultures. The LTC-IC in the striped well was conserved and had proliferated because LTC-IC were detected in 4 of the 8 secondary stromal cultures. Finally, the LTCIC in the dotted well was lost, because none of the wells present in the 8 secondary plates contained an LTC-IC. In this hypothetical example, 3 LTC-IC were present in treshly sorted cells, whereas after 5 woeks of culture 5 total LTC-IC were recovered.

LTC-IC can initiate at least 2 secondary stromal cultures. The type and number of CFC generated by a freshly sorted LTC-IC cultured immediately in contact with stroma or a secondary LTC-IC obtained in progeny of a single sorted cell that was subjected to expansion conditions for 4 to 5 weeks was similar. Furthermore, the type and number of clonogenic cells derived from LTC-IC that had proliferated during the initial expansion culture ( 1 of the multiple LTC- 
Fig 3. (Cont'd) (B) and (C) depict results of 7 and 6 separate experiments in which $\mathrm{CD}_{3} 4^{+} / \mathrm{CD}_{3} 3^{-}$cells we cultured for 5 weeks in stroma-conditioned media supplemented with the indicated cytokines, had their progeny at week 5 divided in $\mathbf{8}$ equal parts, and were replated in contact with stromal feeders. For each experiment, the number of LTC-IC conserved after 5 weeks is indicated (ie, at least 1 of 8 wells of the 8 secondary cultures contained an LTC-IC), the degree of proliferation is indicated $(2,3,4,5,6,7$, or 8 of 8 secondary wells contained an LTC-IC), and the total number of LTC-IC recovered after the initial 5 weeks of culture is depicted.

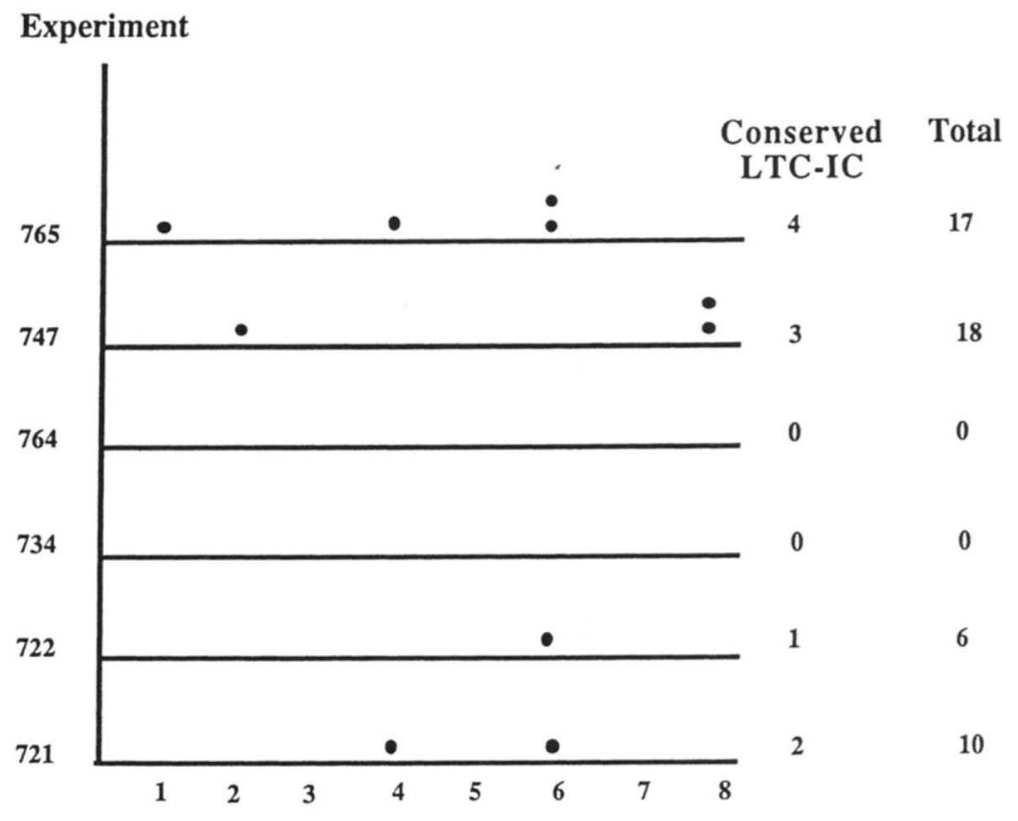

Number of secondary LTBMC initiated $>1$ = LTC-IC proliferation
IC obtained from a single sorted cell) was similar to those derived from an LTC-IC that was simply conserved during the initial culture period (the only LTC-IC present in singlecell progeny). This finding indicates that secondary LTC-IC have similar functional capacity as those in the nonexpanded cell population and suggests that these LTC-IC have under- gone one or more self-renewing cell divisions during the initial culture period.

However, by 4 to 5 weeks of culture, $65 \%$ of LTC-IC in IL-3 + MIP- $1 \alpha$ supplemented cultures and greater than $80 \%$ of LTC-IC cultured in IL-3 + IL-6 + IL- $11+$ MIP- $1 \alpha$ supplemented cultures were lost or were not conserved. Al-

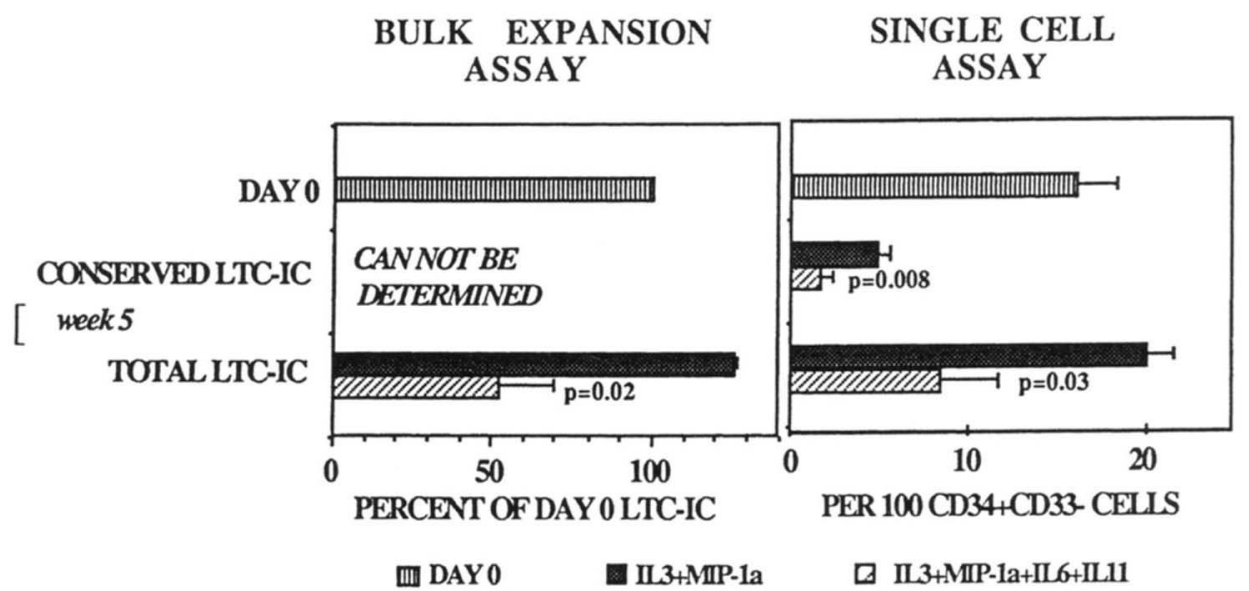

Fig 4. LTC-IC maintenance in the presence of stroma-conditioned media and IL-3 + MIP-1 $\alpha$ is the result of proliferation of conserved LTCIC. Bulk expansion assays ( $n=9$ for IL-3 + MIP- $1 \alpha$ and $n=5$ for IL-3 + MIP- $1 \alpha+$ IL- $6+$ IL-11) and single-cell proliferation assays ( $n=7$ for IL-3 + MIP-1 $\alpha$ and $n=6$ for IL-3 + MIP-1 $\alpha+$ IL- 6 + IL-11) were performed as described in the Materials and Methods and the legends of Figs 1 and 3. This figure shows that the total number of LTC-IC from single-cell proliferation assays in the presence of IL-3 + MIP- $1 \alpha$ is similar to the number of LTC-IC present in freshly sorted CD34 ${ }^{+} \mathrm{CD}_{3}{ }^{-}$cells. When examined in bulk cultures, LTC-IC are maintained when cultured stroma-noncontact cultures supplemented with IL-3 + MIP-1 $\alpha$. Similarly, assessment of the total number of LTC-IC recovered from cultures with IL-3 + MIP-1 $\alpha+$ IL- 6 + IL-11 is similar when determined either by single-cell proliferation or bulk expansion assays. This indicates that single-cell proliferation assays and bulk proliferation can both assess LTC-IC maintenance (total LTC-IC recovered). However, as shown, bulk proliferation assays cannot assess whether maintenance is the result of conservation without proliferation of a large proportion of individual LTC-IC or conservation of only a fraction of LTC-IC that then undergoes extensive proliferation. 
though this assay cannot discriminate between terminal differentiation and cell death such as apoptosis underlying the loss of LTC-IC, the observation that increasing numbers of growth promoting cytokines results in greater loss of LTCIC may favor the former hypothesis. These studies show that evaluation of the progeny of individual ex vivo cultured LTC-IC for their capacity to initiate and sustain 1 or more secondary long-term stromal cultures now allows us to determine if culture conditions support proliferation of LTC-IC without inducing their terminal differentiation or death.

Although single-cell deposition assays provide insight in both processes thought to be responsible for the overall ex vivo expansion of LTC-IC, namely proliferation and conservation, these assays are cumbersome and lengthy. We therefore examined if PKH-26 labeling could replace the singlecell proliferation assay to determine the fate of LTC-IC. We show that assessment of proliferation using either the singlecell proliferation assay or the $\mathrm{PKH}-26$-labeling assay provides identical results. We demonstrated in the single-cell proliferation assay that approximately $80 \%$ of conserved LTC-IC proliferated, which is similar to what is determined by $\mathrm{PKH}-26$-labeling experiments. This indicates that, although LTC-IC proliferation is measured after 2 weeks of culture in PKH-26 assays and after 5 weeks of culture in single LTC-IC proliferation assay, the percentage of LTC$\mathrm{IC}$ that proliferated as measured in the $\mathrm{PKH}-26$ assay correlates with that detected in the single LTC-IC proliferation assays. The major advantage of the PKH-26-labeling assays is that insights in proliferation inducing factors can be gained in approximately 7 weeks rather than the 14 weeks required to perform single-cell proliferation assays. However, $\mathrm{PKH}-$ 26-labeling assays cannot determine if individual LTC-IC were conserved, a factor as important as LTC-IC proliferation in the long-term expansion of LTC-IC. Therefore, single-cell proliferation studies will be required to determine not only if LTC-IC proliferated but also if they are conserved or lost over time.

All studies presented here suggest that the lack of longterm LTC-IC expansion is not due to failure of growthpromoting cytokines ${ }^{25,26}$ to induce LTC-IC proliferation but to the fact that the culture conditions are not conducive for long-term conservation of LTC-IC in an immature, undifferentiated state. It may thus be necessary to use either lower concentrations of the growth-promoting cytokines and/or a combination of presumed growth-inhibitory cytokines, such as additional chemokines ${ }^{27}$ or the chalone serpasine (AcSDKP), ${ }^{28}$ to allow for sufficient LTC-IC proliferation while conserving a larger proportion of LTC-IC, ultimately leading to long-term LTC-IC expansion. In addition, we have shown that LTC-IC cultured in contact with intact stromal feeders proliferate less than when cultured separated from stroma. ${ }^{16-18}$ This is at least in part due to adhesive interactions between progenitors and stromal components, ${ }^{29.30}$ which provide a direct antiproliferative signal. Whether these interactions will also be required to inhibit terminal differentiation and thus conserve primitive progenitors is not known. $\mathbf{R e}$ examination of the role of direct contact between progenitors and specific ligands in the stroma, which may not be released in stromal supernatants, in the long-term ex vivo expansion of LTC-IC may therefore be needed.
In conclusion, we describe a novel single-cell proliferation assay that can evaluate the fate of individual LTC-IC in culture. We show that a fraction of primitive progenitors present in adult human marrow proliferate ex vivo when cultured in the presence of stromal factors, growth-promoting, and presumed growth-inhibitory cytokines. However, a significant number of LTC-IC are not conserved under these culture conditions, possibly as a result of terminal differentiation. This indicates the need for additional antidifferentiation or conservation factors to obtain long-term ex vivo expansion of human hematopoietic stem cells.

\section{ACKNOWLEDGMENT}

We thank Peter Catanzarro, Kirk Vanoverbeek, and Brad Anderson for their excellent technical help.

\section{REFERENCES}

1. Berenson RJ, Bensinger WI, Hill RS, Andrews RG, GarciaLopez J, Kalamasz DF, Still BJ, Spitzer G, Buckner CD, Bernstein ID: Engraftment after infusion of $\mathrm{CD} 34^{+}$marrow cells in patients with breast cancer or neuroblastoma. Blood 77:1717, 1991

2. Andrews RG, Bryant EM, Bartelmez SH, Muirhead DY, Knitter $\mathrm{GH}$, Bensinger W, Strong DM, Bernstein ID: CD34+ marrow cells, devoid of $\mathrm{T}$ and B lymphocytes, reconstitute stable lymphopoiesis and myelopoiesis in lethally irradiated allogeneic baboons. Blood 80:1693, 1992

3. Verfaillie CM, Miller WJ, Boylan K, McGlave PB: Selection of benign primitive hematopoietic progenitors in chronic myelogenous leukemia on the basis of HLA-DR antigen expression. Blood 79:1003, 1992

4. Gluckman E, Broxmeyer HE, Auerbach AD, Friedman HS, Douglas GW, Devergie A, Esperou H, Thierry D, Socie G, Lehn P, Cooper S, English D, Kurtzberg J, Bard J, Boyse EA: Hematopoietic reconstitution in a patient with Fanconi's anemia by means of umbilical-cord blood from an HLA-identical sibling. $N$ Engl J Med 321:1174, 1989

5. Rill DR, Moen RC, Buschle M, Bartholomew C, Foreman NK, Mirro J, Krance RA, Ihle JN, Brenner MK: An approach for the analysis of relapse and marrow reconstitution after autologous marrow transplantation using retrovirus-mediated gene transfer. Blood $79: 2694,1992$

6. van Beusechem V, Kukler A, Heidt P, Valerio D: Long-term expression of human adenosine deaminase in rhesus monkeys transplanted with retrovirus-infected bone-marrow cells. Proc Natl Acad Sci USA 89:7640, 1992

7. Miller DG, Adam MA, Miller AS: Gene transfer by retrovirus occurs only in cells that are actively replicating at the time infection. Mol Cell Biol 10:4239, 1989

8. Allen TD, Dexter TM: Long term marrow cultures: An ultrastructural review. Scanning Electron Microsc 4:1851, 1983

9. Koller MR, Emerson SG, Palsson BR: Large-scale expansion of human stem and progenitor cells from marrow mononuclear cells in continuous perfusion cultures. Blood 82:378, 1993

10. Barnett MJ, Eaves CJ, Philips GL, Kalousek KD, Klingeman HG, Landsdorp PM, Reece DE, Sheperd JD, Shaw GJ, Eaves AC: Successful autografting in chronic myelogenous leukemia after maintenance of marrow in culture. Bone Marrow Transpl 4:345, 1989

11. Fraser C, Szilvassy S, Eaves C, Humphries R: Proliferation of totipotent hematopoietic stem cells in vitro with retention of longterm competitive in vivo reconstituting ability. Proc Natl Acad Sci USA 89:1968, 1992

12. Haylock DN, To LB, Dowse TL, Juttner CA, Simmons PJ: 
Ex vivo expansion and maturation of peripheral blood $\mathrm{CD} 34^{+}$cells into the myeloid lineage. Blood 80:1405, 1992

13. Brandt J, Srour E, Van Besien K, Bridell R, Hoffman R: Cytokine-dependent long-term culture of highly enriched precursors of hematopoietic progenitor cells from human marrow. J Clin Invest 86:932, 1990

14. Terstappen LWMM, Huang S, Safford M, Landsdorp P, Loken $M$ : Sequential generation of hematopoietic colonies derived from single nonlineage-committed $\mathrm{CD} 34^{+} \mathrm{CD} 38^{-}$progenitor cells. Blood $77: 1218,1991$

15. Landsdorp PM, Dragowska W, Mayani H: Ontogeny-related changes in proliferative potential of human hematopoietic cells. $\mathrm{J}$ Exp Med 178:787, 1993

16. Verfaillie CM: Direct contact between human primitive hematopoietic progenitors and marrow stroma is not required for longterm in vitro hematopoiesis. Blood 79:2821, 1992

17. Verfaillie CM, Li W-N, Catanzarro P: MIP- $1 \alpha$ combined with IL3 maintains primitive human LTBMC-IC for at least 8 weeks in ex vivo "stroma-noncontact" cultures. J Exp Med 179:643, 1994

18. Verfaillie CM: Soluble factor(s) produced by human marrow stroma increase cytokine induced proliferation and maturation of primitive hematopoietic progenitors while preventing their terminal differentiation. Blood 82:2045, 1993

19. Sutherland HJ, Cashman JD, Henkelman DH, Eaves AC, Eaves CJ: Functional characterization of individual human hematopoietic stem cells cultured at limiting dilution on supportive marrow stroma. Proc Natl Acad Sci USA 87:3584, 1989

20. Verfaillie C, Blakolmer K, McGlave P: Purified primitive human hematopoietic progenitor cells with long-term in vitro repopulating capacity adhere selectively to irradiated BM stroma. J Exp Med 172:509, 1990

21. Burrhoughs JM, Gupta P, Verfaillie CM: Soluble factors from the mouse fibroblast cell line M210-B4 support in vitro hematopoiesis. Exp Hematol 2:1095, 1994
22. Sutherland HJ, Eaves CJ, Landsdorp PM, Thaker JD, Hogge DE: Differential regulation of primitive human hematopoietic cells in long-term marrow cultures maintained on genetically engineered murine stromal cells. Blood 78:666, 1991

23. Horan PK, Melnicoff MJ, Jensen BD, Slezak SE: Fluorescent cell labeling for in vivo and in vitro cell tracking. Methods Cell Biol $33: 469,1990$

24. Verfaillie CM, Miller JS: $\mathrm{CD}^{+} / \mathrm{CD}^{-} 33^{-}$cells reselected from "stroma-noncontact" cultures contain more than 20 percent primitive progenitors capable of long-term in vitro hematopoiesis. Blood 84:1442, 1994

25. Leary AG, Ikebuchi K, Hirai Y, Wong GG, Yang Y-C, Clark SC, Ogawa M: Synergism between interleukin- 6 and interleukin3 in supporting proliferation of human hematopoietic stem cells: Comparison with interleukin-1. Blood 71:1759, 1988

26. Paul SR, Bennet F, Calvetti JA, Kelleher K, Wood CR, O'Hara RM Jr, Leary AS, Sibley B, Clark SC, Williams DA, Yang Y-C: Molecular cloning of a cDNA encoding interleukin 11, a stromal cell-derived lymphopoietic and hematopoietic cytokine. Proc Natl Acad Sci USA 87:7512, 1990

27. Lu L, Xiao M, Grigsby S, Wange WX, Wu B, Shen R, Broxmeyer HE: Comparative effects of suppressive cytokines on isolated single CD34 +++ stem/progenitor cells from human marrow and umbilical cord blood plated with and without serum. Exp Hematol 21:1442, 1993

28. Pontvert-Delucq S, Baillou C, Najman A, Guigon M: Direct and reversible inhibitory effect of the tetrapeptide acetyl-n-ser-asplys-pro on the growth of human $\mathrm{CD} 34^{+}$subpopulations in response to growth factors. Blood 82:3307, 1993

29. Hurley R, Verfaillie CM: Direct contact with marrow stroma has negative regulatory effects on hematopoietic progenitors. Blood 82:71a, 1993 (abstr, suppl 1)

30. Verfaillie CM, Catanzarro P, Miller JS: An in vitro assay that can determine the fate of single sorted LTC-IC. Blood 84:367a, 1994 (abstr, suppl 1) 